\title{
Quality characteristics of kimchi prepared with cut Kimchi cabbages during the short-term storage
}

\author{
Eun Ji Son ${ }^{1}$, Kim Sang Seop ${ }^{2}$, Shin-Kyo Chung ${ }^{1,3 *}$ \\ ${ }^{1}$ School of Food Science and Biotechnology, Kyungpook National University, Daegu 41566, Korea \\ ${ }^{2}$ Food Distribution System Research Group, Korea Food Research Institute, Seongnam 13539, Korea \\ ${ }^{3}$ Food and Bio-industry Research Institute, Kyungpook National University, Daegu 41566, Korea
}

\section{단기저장 절단배추 김치의 품질 특성}

\author{
손은지 ${ }^{1} \cdot$ 김상섭 $^{2} \cdot$ 정신교 ${ }^{1,3 *}$ \\ ${ }^{1}$ 경북대학교 식품공학부, ${ }^{2}$ 한국식품연구원 저장유통연구단, ${ }^{3}$ 경북대학교 식품생물산업연구소
}

\begin{abstract}
Cut Kimchi cabbages $(3 \times 3 \mathrm{~cm})$ were dipped in the egg shell solution $(0.5 \%$ egg shell calcium/ $/ 0.5 \%$ citric acid solution) and stored in the low-density polyethylene (LDPE) film bag at $4{ }^{\circ} \mathrm{C}$ for 2 weeks. Using this cut Kimchi cabbage, kimchi was prepared and their physicochemical qualities were investigated. Moreover, their sensory qualities were compared with Kimchi prepared with normal Kimchi cabbages. Egg shell calcium pretreatment (ET) showed the lower weight loss of cabbages than non-treatment (NT), and soluble solid compounds were decreased in all samples. Titratable acidity showed no statistical difference. After making a kimchi using cut Kimchi cabbages stored for 2 weeks no statistical differences in soluble solids and titratable acidities of kimchi stored for 7 days were shown. As a result of sensory test, preference of color was decreased and salted condition of control was the most significantly decreased. Pickled seafood odor of kimchi showed statistical difference, compared with the control. Crispness decreased in all samples. On the other hand, salty flavor and pickled seafood flavor were increased, fresh cabbage flavor, bitter flavor and carbonic flavor were decreased. Overall sensory quality of cut Kimchi cabbage (ETK) didn't show significant difference compare with kimchi prepared with normal cabbage (CON). It is possible to make kimchi with approvable sensory quality using cut Kimchi cabbage treated with egg shell calcium.
\end{abstract}

Key words : cut Kimchi cabbages, egg shell calcium, organic acid, short-term storage, quality

\section{서 론}

김치는 배추, 무, 오이 등의 여러 가지 채소류를 소금에 절인 후, 마늘, 고추 등의 향신료와 젓갈 등의 부재료를 첨가하여 일정기간 숙성시키는 우리나라 고유의 전통 발효 식품으로, 현재까지도 우리의 식생활에서 큰 비중을 차지 하고 있다(1-3). 김치는 식이섬유소, 비타민, 무기질 등의

*Corresponding author. E-mail : kchung@knu.ac.kr

Phone : 82-53-950-5778, Fax : 82-53-950-6772

Received 22 November 2016; Revised 9 March 2017; Accepted 31 March 2017.

Copyright (c) The Korean Society of Food Preservation. All rights reserved.
공급원이며(4,5) 발효 중 유기산과 젖산균의 생성이 풍부함 은 물론 주재료와 부재료에 함유된 페놀, 플라보노이드, 베타카로틴 등에 의한 비만억제(6), 항노화효과(7), 항암효 과(8), 동맥경화억제효과(9), 항균작용(10) 등과 같은 생리 활성을 가지는 것으로 밝혀지면서 국제적으로 그 우수성이 인정되고 있다 $(2,3)$. 김치가 세계적인 식품이 됨에 따라 미 국, 일본, 대만 홍콩 등 여러 국가에 김치가 수출되거나, 현지에서 제조 및 판매되고 있다 $(4,11)$. 김치의 유통 중 저장 성 및 안전성에 대한 문제의 해결과 김치의 세계화를 위한 기능성 증대와 선도 유지를 위한 방안으로 원부재료, 발효, 숙성, 저장 유통, 제조와 안전성 등 여러 분야에 걸쳐서 연구가 매우 활발히 진행되고 있다 $(12,13)$.

신선 과채류의 저장성을 높이기 위한 열처리 기술은 농 
산물의 노화를 억제하고, 저온장해를 완화시키며 유해 미 생물의 제어나 살균에도 효과적이며(14-16), 열수에 담그거 나 열수나 스팀을 분무하거나 가열된 공기를 하는 방법 등이 있다(17).

칼슘은 과실이나 채소의 세포벽 구조를 유지하는데 중요 한 역할을 하여 숙성을 지연시키고, 세포벽 붕괴로 인한 연화를 억제시키는 효과가 있다(18). 본인 등은 칼슘과 구연 산 병용 처리와(19) 난각 칼슘 처리(20)가 절단배추의 단기 저장에 미치는 선도 유지 효과를 보고하였다.

본 연구에서는 이 방법에 따라서 단기저장한 절단배추로 김치를 제조하여 이의 이화학적 및 관능적 품질 특성을 조사하여 보고하는 바이다.

\section{재료 및 방법}

\section{실험재료 및 전처리}

본 실험에서 사용한 배추는 전라남도 해남군에서 2015년 도에 노지 재배한 가을배추인 '추광' 품종을 사용하였다. 난각칼슘은 성 등(20)에 따라 제조된 것을 사용하였다. 배추 를 2 분간 $45^{\circ} \mathrm{C}$ 의 난각칼슘 전처리 용액 $(0.5 \%$ 난각칼슘 $+0.5 \%$ 구연산)에 침지하고 탈수한 후, 일정한 크기 $(3 \times 3 \mathrm{~cm})$ 로 절 단하였다(egg shell calcium pretreatment, ET). 대조구 (non-treatment, NT)는 같은 방법으로 상온의 증류수를 사용 하였다. 절단된 배추는 $1 \mathrm{~kg}$ 씩 LDPE film백 $(40 \times 50 \mathrm{~cm}, 0.5$ $\mathrm{mm})$ 에 넣어 $4^{\circ} \mathrm{C}$ 에서 냉장 저장하며, 2 주간 이화학적 품질 특성을 조사하였다.

\section{김치의 제조}

난각칼슴/구연산 용액에 침지하여 2 주간 저장한 절단배 추로 김치를 제조하였다(kimchi prepared by egg shell calcium pretreatment cut Kimchi cabbages, ET-K). 대조구는 증류수 침지 및 저장한 절단배추로 제조하였다(kimchi prepared by non-treatment cut Kimchi cabbages, NT-K). NT-K와 ET-K는 배추 무게의 2 배에 해당하는 $5 \%$ 소금물에 서 1 시간 염장을 실시하였으며, control(CON)은 일반 배추 를 4 등분하여 $5 \%$ 소금물에서 3 시간 염장하였다. 이후 흐르 는 물에 3회 세척하고 1 시간 탈수한 후 배추 $100 \mathrm{~g}$ 에 대하여 무 15 , 기타 부재료 17.5 (쑥갓 5 , 멸치젓 4 , 미나리 3 , 마늘 2 , 고춧가루 1.5 , 생강 1 , 설탕 1$)$ 의 비율로 구성된 양념을 혼합하여 김치를 제조하였다. 뚜껑이 있는 플라스틱 밀폐 용기에 넣어 밀봉하고, 상온에서 1 일 동안 숙성한 다음, 저온 저장고 $\left(4^{\circ} \mathrm{C}\right)$ 에서 1 주일 동안 저장하여 각각 이화학적 특성을 측정하고 관능검사를 실시하였다.

\section{이화학적 품질특성}

절단배추 및 김치의 이화학적인 품질특성은 중량 변화,
가용성 고형분 함량 및 적정 산도와 $\mathrm{pH}$ 를 측정하였다(19). 절단배추의 중량 감소율은 매주 칭량하여 초기 중량과 이후 측정된 시료의 중량을 초기 중량에 대한 백분율(\%)로 나타 내었다. 가용성 고형분 함량은 배추 또는 김치 시료 $10 \mathrm{~g}$ 에 증류수 $10 \mathrm{~mL}$ 를 가하여 분쇄하고 여과한 여과액의 200 $\mu \mathrm{L}$ 를 취해 굴절 당도계(Master-a, Atage Co., Tokyo, Japan) 로 측정하였다. 적정 산도는 위의 여과액 $1 \mathrm{~mL}$ 를 증류수 $19 \mathrm{~mL}$ 와 혼합하여 20배 희석한 시료를 $0.01 \mathrm{~N}$ sodium hydroxide로 $\mathrm{pH}$ 8.3이 될 때까지 적정한 후 소비된 sodium hydroxide의 양을 측정하여 구하였다(21). $\mathrm{pH}$ 는 여과액을 pH meter(Mettler Toledo MP220, Mettler Toledo Co., Schwerzenbach, Switzerland)로 측정하였다.

\section{관능검사}

관능검사는 $\operatorname{Kim}(22)$ 의 방법으로 정량적 묘사분석을 실 시하였다. 패널원은 경북대학교 식품공학과 학부 및 대학 원생 15 명을 대상으로 외관, 냄새, 향미, 조직감, 전반적 기호도에 대해 9점 기호 척도법으로 실시하였다.

\section{통계분석}

모든 실험결과는 3 회 반복하여 평균(Mean)표준편차 (Standard deviation, SD)로 표시하였다. ANOVA 분석을 행 한 후 $\mathrm{p}<0.05$ 수준에서 Duncan's multiple range test를 실시 하여 유의성을 검증하였으며, Statistic Analysis System(SAS v 9.4 Institute Inc., Cary, NC, USA) 통계프로그램을 이용하 였다.

\section{결과 및 고찰}

\section{단기저장 절단배추와 김치의 이화학적 품질특성}

절단배추의 전처리에 따른 이화학적 품질특성은 Table 1 과 같다. 중량은 저장기간이 지남에 따라 유의적으로 낮아 졌으며 $(\mathrm{p}<0.05)$, 저장 2 주차의 중량은 99.92-99.93\%의 범위 로 나타났다. NT에 비하여 ET의 중량 감소율이 낮았다. 과채류의 저장 중 중량 감소는 주로 증산 작용에 의해 일어 나는 것으로(23), 이에 중량 보존은 유통 및 판매과정에서 시듦 현상을 방지하여 외관품질을 우수하게 유지하는데 필수적인 사항으로 요구된다(24). 가용성 고형분 함량은 $\mathrm{NT}$ 와 ET 모두 감소하는 경향을 보였다. NT는 2 주의 저장기 간 동안 $14.29 \%$ 감소하였으며, ET는 $18.97 \%$ 감소하였으나, $\mathrm{NT}$ 와 ET의 가용성 고형분 함량에 대한 유의차는 나타나지 않았다(p<0.05). 적정산도의 변화를 측정한 결과, 초기 적정 산도는 $0.07 \%$ 로, 저장 기간 동안 유의적인 변화는 나타나지 않았다 $(\mathrm{p}<0.05)$. 저장 1 주차에서 $\mathrm{ET}$ 의 적정산도가 $\mathrm{NT}$ 에 비해 증가하였으나, 저장 2 주차에는 $0.06 \%$ 로 $\mathrm{NT}$ 와 $\mathrm{ET}$ 의 차이가 나타나지 않았다. 저장 중 $\mathrm{pH}$ 변화의 경우, 배추의 
초기 $\mathrm{pH}$ 는 6.40-6.45의 범위로 나타났다. NT와 ET 모두 저장기간 동안 증가하다가 감소하는 경향을 보였지만, 결 과적으로 $\mathrm{NT}$ 의 $\mathrm{pH}$ 는 유의적으로 증가한 것과 달리 $\mathrm{ET}$ 의 $\mathrm{pH}$ 는 감소하였다 $(\mathrm{p}<0.05)$. 절임배추는 저장 중 배추 내의 당분이 젖산 등의 유기산으로 발효되어 $\mathrm{pH}$ 가 감소하고 산 도가 증가한다(25). 본 연구는 $\operatorname{Han}$ 등(25)의 연구에 비해 저장 기간이 짧아서 유의차가 나타나지 않은 것으로 생각된 다. 그러나 절단배추를 동일한 조건에서 6주 동안 저장하였 을 때 난각칼슘 처리가 선도유지에 효과가 있었다고 보고되 었다(19).

Table 1. Physicochemical properties of cut Kimchi cabbages with egg shell calcium pretreatment stored at $4^{\circ} \mathrm{C}$ for 2 weeks

\begin{tabular}{|c|c|c|c|c|}
\hline & \multirow{2}{*}{ Samples ${ }^{1)}$} & \multicolumn{3}{|c|}{ Weeks } \\
\hline & & 0 & 1 & 2 \\
\hline \multirow{2}{*}{ Weight loss (\%) } & NT & $100 \pm 0.00^{\mathrm{aA} 2)}$ & $99.97 \pm 0.01^{\mathrm{bA}}$ & $99.92 \pm 0.01^{\mathrm{CB}}$ \\
\hline & ET & $100 \pm 0.00^{\mathrm{aA}}$ & $99.98 \pm 0.01^{\mathrm{bA}}$ & $99.93 \pm 0.00^{\mathrm{cA}}$ \\
\hline \multirow{2}{*}{$\begin{array}{l}\text { Soluble solid } \\
\text { content ( }{ }^{\circ} \text { Brix) }\end{array}$} & NT & $1.87 \pm 0.31^{\mathrm{aA}}$ & $1.77 \pm 0.12^{\mathrm{aA}}$ & $1.60 \pm 0.17^{\mathrm{aA}}$ \\
\hline & ET & $1.93 \pm 0.12^{\mathrm{aA}}$ & $1.67 \pm 0.15^{\mathrm{bA}}$ & $1.57 \pm 0.12^{\mathrm{bA}}$ \\
\hline \multirow{2}{*}{$\begin{array}{l}\text { Titratable acidity } \\
(\%)\end{array}$} & NT & $0.07 \pm 0.01^{\mathrm{aA}}$ & $0.06 \pm 0.01^{\mathrm{aB}}$ & $0.06 \pm 0.00^{\mathrm{aA}}$ \\
\hline & ET & $0.07 \pm 0.00^{\mathrm{bA}}$ & $0.11 \pm 0.00^{\mathrm{aA}}$ & $0.06 \pm 0.00^{\mathrm{cA}}$ \\
\hline \multirow{2}{*}{$\mathrm{pH}$ value } & NT & $6.40 \pm 0.01^{\mathrm{C}^{\mathrm{B}}}$ & $6.67 \pm 0.06^{\mathrm{aA}}$ & $6.59 \pm 0.02^{\mathrm{bA}}$ \\
\hline & ET & $6.45 \pm 0.01^{\mathrm{bA}}$ & $6.66 \pm 0.01^{\mathrm{aA}}$ & $6.41 \pm 0.01^{\mathrm{cB}}$ \\
\hline
\end{tabular}

${ }^{1)} \mathrm{NT}$, non-treatment; ET, egg shell calcium pretreatment.

2)-c-ceans followed by the same letters within the row of each Kimchi cabbages are not significantly different $(\mathrm{p}<0.05),{ }^{\mathrm{A}-\mathrm{C}}$ means followed by the same letters within the column per parameter are not significantly different $(\mathrm{p}<0.05)$.
2주간 저장한 절단배추를 이용하여 김치를 제조한 후 숙성 1주일째에 이화학적 품질특성을 측정한 결과는 Table 2 와 같다. 이 때, $\mathrm{CON}$ 은 일반 배추김치로 하여 NT-K, ET-K 와 비교하였다. 가용성 고형분 함량은 CON, ET-K, NT-K 순으로 높았으나 유의적인 차이를 나타내지 않았다 $(\mathrm{p}<0.05)$. 적정산도 또한 가용성 고형분 함량과 마찬가지로 유의적인 차이를 나타내지 않았으나, 그 값은 NT-K, ET-K 가 비슷한 값을 나타내었으며, $\mathrm{CON}$ 이 더 낮은 함량을 보였 다. $\operatorname{Kim}(26)$ 의 연구에서, 소금 농도와 종류를 달리한 김치 의 적정산도를 측정하였을 때 숙성 1 주일째에 $10 \%$ 소금물 에 염장한 경우 산도가 $0.36-0.43 \%, 15 \%$ 소금물에 염장한 경우 0.44-0.46\%로 나타나 소금물 농도가 높아짐에 따라 적정산도가 높아짐을 알 수 있었다. 이에 따라 $5 \%$ 소금물로 염장한 본 연구의 김치에서는 $0.19-0.20 \%$ 로 측정되어 산도 가 다소 낮음을 확인했다. $\mathrm{pH}$ 의 경우, NT-K가 더 낮은 $\mathrm{pH}$ 값을 보였으며, $\mathrm{CON}$ 과 ET-K는 유의적인 차이를 나타내지 않았다(p<0.05). $\operatorname{Kim}(26)$ 의 연구에서, 소금 농도와 종류를

Table 2. Physicochemical properties of kimchi prepared with cut Kimchi cabbages stored at $4^{\circ} \mathrm{C}$ for 1 week

\begin{tabular}{cccc}
\hline Samples ${ }^{1)}$ & CON & NT-K & ET-K \\
\hline Soluble solid content ( ${ }^{\circ}$ Brix) & $5.03 \pm 0.06^{\mathrm{a} 2)}$ & $4.87 \pm 0.15^{\mathrm{a}}$ & $4.97 \pm 0.15^{\mathrm{a}}$ \\
Titratable acidity (\%) & $0.19 \pm 0.02^{\mathrm{a}}$ & $0.20 \pm 0.01^{\mathrm{a}}$ & $0.20 \pm 0.01^{\mathrm{a}}$ \\
$\mathrm{pH}$ value & $5.74 \pm 0.02^{\mathrm{a}}$ & $5.62 \pm 0.03^{\mathrm{b}}$ & $5.71 \pm 0.01^{\mathrm{a}}$ \\
\hline
\end{tabular}

${ }^{1)} \mathrm{CON}$, control; NT-K, kimchi prepared by non-treatment cut Kimchi cabbages; ET-K, kimchi prepared by egg shell calcium pretreatment cut Kimchi cabbages.

${ }^{2) a-c}$ Means followed by the same letters within the row of each Kimchi cabbages are not significantly different $(\mathrm{p}<0.05)$.

Fig. 1. Photos of kimchi prepared with cut Kimchi cabbages.

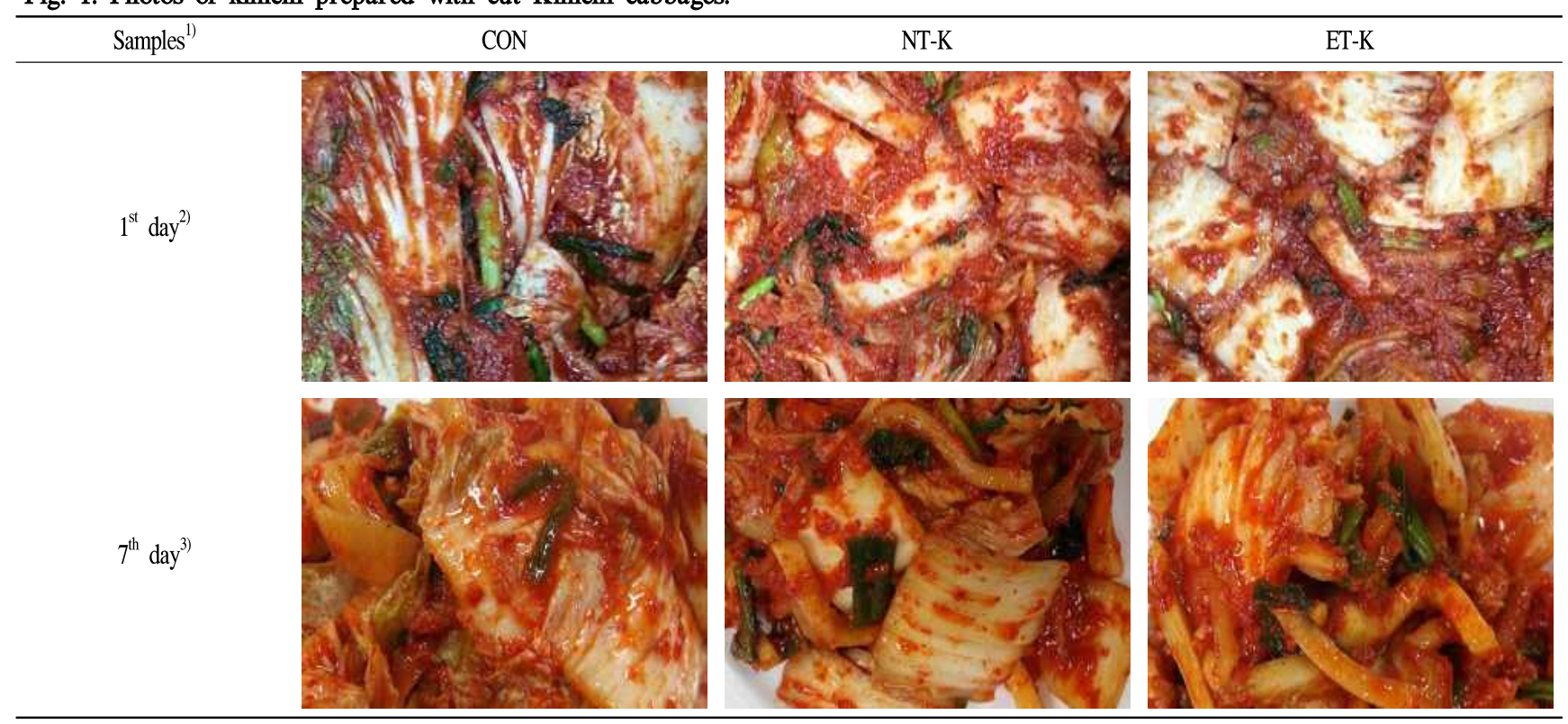

\footnotetext{
${ }^{11} \mathrm{CON}$, control; NT-K, kimchi prepared by non-treatment cut Kimchi cabbages; ET-K, kimchi prepared by egg shell calcium pretreatment cut Kimchi cabbages.

${ }^{2}$ One day storage at room temperature.

${ }^{3)}$ Srore at room temperature for 1 day and store at $4^{\circ} \mathrm{C}$.
} 
달리한 김치의 $\mathrm{pH}$ 를 측정하였을 때 숙성 6 일째에 $\mathrm{pH}$ 가 $10 \%$ 소금물에 염장한 경우 4.78-5.10, $15 \%$ 소금물에 염장한 경우 4.49-4.89로 나타나 소금물 농도가 높아짐에 따라 $\mathrm{pH}$ 가 낮아짐을 알 수 있었다. 이에 따라 $5 \%$ 소금물로 염장한 본 연구의 김치에서는 5.62-5.74로 측정되어 $\mathrm{pH}$ 가 다소 높 음을 확인했다.

\section{절단배추 김치의 관능적 특성}

김치의 중요한 품질 지표인 관능적 특성에 관여하는 주 요 요소는 맛, 냄새, 조직감 그리고 색이며, 김치의 맛은 신맛, 감칠맛, 짠맛, 단맛 등이 조화를 이룬다 $(27,28)$.

김치 제조 후 숙성 1 일, 1 주일째의 외관은 Fig. 1 에 나타내 었으며, 이때 실시한 관능검사의 결과는 Fig. 2와 같다. 외관
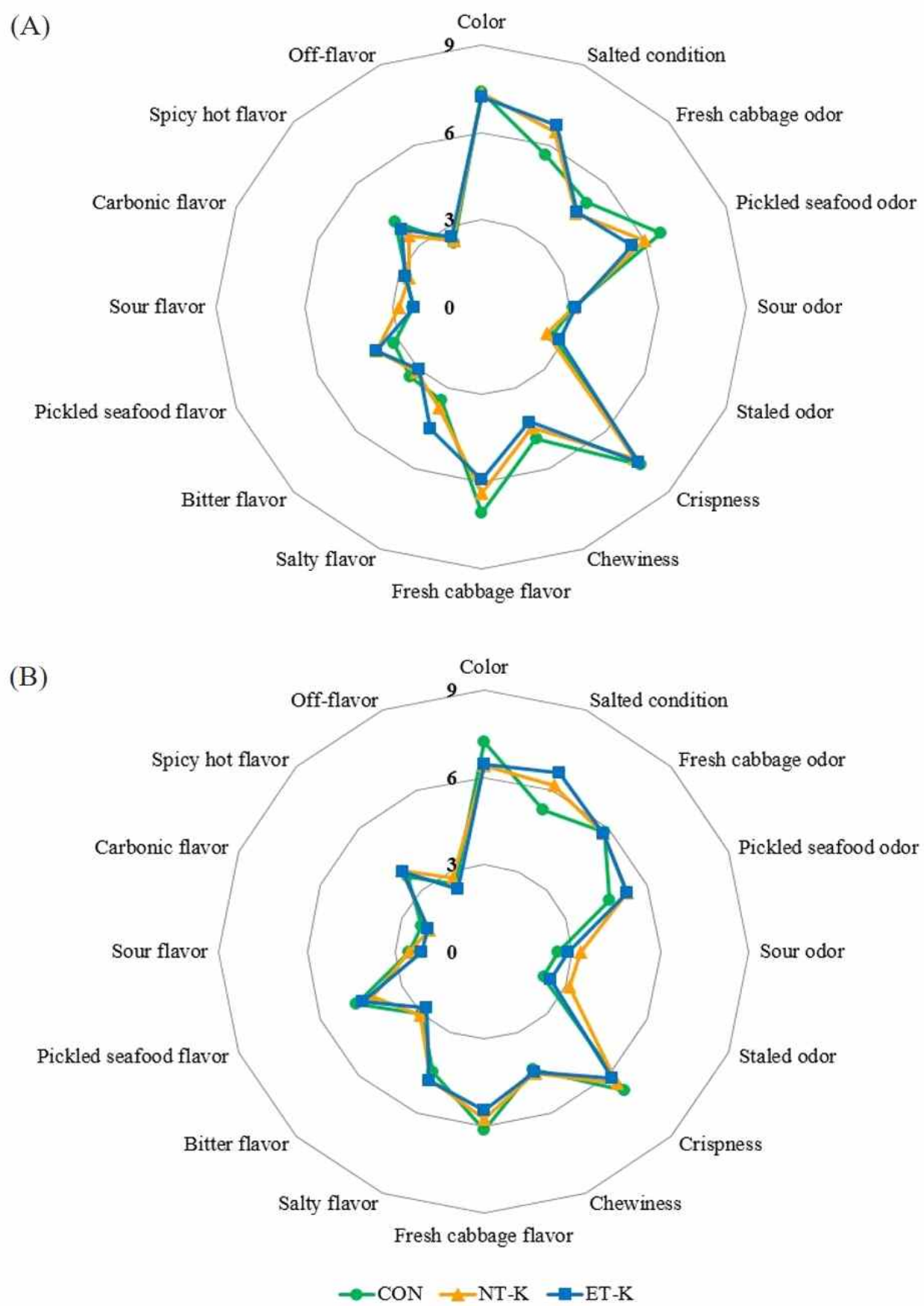

Fig. 2. Quantitative descriptive analysis profiles of the sensory qualities of kimchi with cut Kimchi cabbage by egg shell calcium pretreatment.

(A), after 1 day; (B), after 7 days.

CON $(\mathbf{O})$, control; NT-K $(\boldsymbol{\Delta})$, kimchi prepared by non-treatment cut Kimchi cabbages; ET-K $(\boldsymbol{\square})$, kimchi prepared by egg shell calcium pretreatment cut Kimchi cabbages. 
을 평가하는 2 가지 항목인 색과 절임상태에서는 숙성 기간 별 유의적인 차이를 보이지 않았으나, 색의 경우 1 일째에서 7.20-7.40, 1주일째에 6.40-7.20으로 색에 대한 기호도는 감 소하였으며, 절임상태는 $\mathrm{CON}$ 에서 가장 크게 감소하였다. 냄새를 평가하는 항목 중 신내(sour odor)는 ET-K가 NT-K 에 비해 낮은 값을 보였다. 젓갈내(pickled seafood odor)는 $\mathrm{CON}$ 에서 1 일째에 $6.60,1$ 주일째에 4.60으로 2점 감소하여 유의적인 차이를 보였다 $(\mathrm{p}<0.05)$. 김치의 조직감은 경도와 아삭아삭한 정도로 나타내며(27), 아삭아삭한 정도는 숙성 기간 동안 모든 시료에서 값이 감소하였으며, 특히 ET-K는 7.53에서 6.13으로 유의적인 차이를 보였으나 처리구와 무 처리구간의 유의적인 차이는 나타나지 않았다 $(\mathrm{p}<0.05)$.

향미는 생배추맛(fresh cabbage flavor), 짠맛(salty flavor), 쓴맛(bitter flavor), 젓갈맛(pickled seafood flavor), 신맛(sour flavor), 탄산맛(carbonic flavor), 매운맛(spicy hot flavor), 군덕맛(off-flavor) 8가지 항목으로 평가하였다. 생배추맛은 1 일째에 $\mathrm{CON}$ 에서 가장 높았으나, 1 주일째에 1.5 점 이상 감소하여 유의적인 차이를 보였다. 짠맛은 3.47-4.53에서 1주일째에 4.47-4.80으로 증가하였으며, 시료에 따른 유의 적인 차이는 보이지 않았다. 쓴맛은 저장 1 일째의 $\mathrm{CON}$ 에서 가장 높았으나, 1 주일째에 가장 큰 폭으로 감소하여 가장 낮게 나타났다. 젓갈맛 또한 시료에 따른 유의적인 차이는 없었으나, 1일째에 3.20-3.87에서 1주일째에 4.07-4.67로 증 가하였다. 탄산맛은 숙성 기간 동안 2.67-2.80에서 2.00-2.27 로 감소하였다. 매운맛은 NT-K에서 숙성 기간 동안 가장 낮게 나타났으며, 군덕맛은 $\mathrm{CON}$ 에서 숙성 기간 동안 가장 낮게 나타났다.

전반적으로 숙성에 따라 김치는 색에 대한 기호도와 함 께 신내, 젓갈내 등이 감소하였으며 향미의 경우 짠맛과 젓갈맛은 증가한 반면, 생배추맛과 쓴맛, 탄산맛은 감소하 였다. 절단배추김치 $(\mathrm{NT}-\mathrm{K}, \mathrm{ET}-\mathrm{K})$ 는 신선도 및 조직감의 특성들이 포기김치 $(\mathrm{CON})$ 에 비하여 떨어지는 것으로 나타 났으나, 유의차는 없었다 $(\mathrm{p}<0.05)$. 따라서 난각칼슘 용액을 처리하여 단기간 저장한 절단배추를 이용하여 비교적 관능 적 품질이 우수한 배추김치를 제조하는 것이 가능한 것으로 사료된다.

\section{요 약}

난각칼숨 용액 $(0.5 \%$ 난각칼슘 $+0.5 \%$ 구연산 $)$ 에 배추를 침지하고 탈수한 후, 절단 $(3 \times 3 \mathrm{~cm})$ 하여 2 주 동안 $4{ }^{\circ} \mathrm{C}$ 에 저 장하고 이를 이용하여 김치를 제조하여 이화학적인 특성과 관능적 품질특성을 조사하였다. 절단배추의 중량은 저장기 간이 지남에 따라 유의적으로 낮아졌으며 $(\mathrm{p}<0.05), \mathrm{NT}$ 에 비하여 ET의 중량 감소율이 낮았다. 가용성 고형분 함량은 $\mathrm{NT}$ 와 ET 모두 감소하였으며, 유의차는 나타나지 않았다 $(\mathrm{p}<0.05)$. 적정산도의 변화를 측정한 결과, 저장 기간 동안 유의적인 변화는 나타나지 않았다 $(\mathrm{p}<0.05) . \mathrm{pH}$ 는 저장기간 동안 증가하다가 감소하는 경향을 보였지만, 결과적으로 $\mathrm{NT}$ 의 $\mathrm{pH}$ 가 유의적으로 증가한 것과 달리 $\mathrm{ET}$ 의 $\mathrm{pH}$ 는 감소 하였다(p<0.05). NT와 ET의 외관을 비교한 결과 초기에는 $\mathrm{NT}$ 가 우수하였으나, 저장 2주 후에는 NT에 비하여 ET의 외관이 밝고 깨끗하였다. 저장한 절단배추를 이용하여 김 치를 제조하여 이화학적 품질특성을 측정한 결과, 가용성 고형분 함량은 CON, ET-K, NT-K 순으로 높았으나 유의적 인 차이를 나타내지 않았다 $(\mathrm{p}<0.05)$. 적정산도 또한 유의적 인 차이를 나타내지 않았으나, 그 값은 NT-K, ET-K가 비슷 한 값을 나타내었으며, $\mathrm{CON}$ 이 더 낮은 함량을 보였다. $\mathrm{pH}$ 의 경우, NT-K가 더 낮은 $\mathrm{pH}$ 값을 보였으며, $\mathrm{CON}$ 과 ET-K 는 유의적인 차이를 나타내지 않았다 $(\mathrm{p}<0.05)$. 관능검사 결 과, 숙성 기간에 따라 모든 구에서 외관은 색에 대한 기호도 와 절임상태 모두 감소하였으며, 냄새는 젓갈내가 유의적 인 차이를 보이며 감소하였고, 신내의 경우 ET-K가 NT-K 에 비해 낮은 값을 보였다. 조직감은 ET-K가 유의적인 감소 를 보였으나, $\mathrm{CON}, \mathrm{NT}-\mathrm{K}$ 와의 유의적인 차이는 나타나지 않았다. 향미는 짠맛과 젓갈맛이 증가한 반면, 생배추맛, 쓴맛, 탄산맛은 감소하였다. 전반적으로 난각칼슘을 처리 절단배추 김치 $(\mathrm{ET}-\mathrm{K})$ 는 일반 배추김치 $(\mathrm{CON})$ 와 관능적으 로 유의적인 차이를 나타내지 않았다 $(\mathrm{p}<0.05)$. 난각칼슘을 처리하여 단기간 저장한 절단배추를 이용하여 품질이 양호 한 김치 제조가 가능한 것으로 사료된다.

\section{References}

1. Jeong ST, Kim JG, Kang EJ (1999) Quality characteristics of winter Chinese cabbage and changes of quality during the kimchi fermentation. Korean J Postharvest Sci Technol, 6, 179-183

2. Kim HM, Kang SW, Woo SW, Lee MH, Heo HJ, Chun JY, William LK, Choi SG (2013) Effect of perilla oil on quality characteristics of cabbage kimchi during fermentation. J Agric Life Sci, 47, 255-266

3. Lee HA, Song YO, Jang MS, Han JS (2013) Effect of Ecklonia cava on the quality kimchi during fermentation. J Korean Soc Food Sci Nutr, 42, 83-88

4. Kim HY, Kil JH, Park KY (2013) Comparing the properties and functionality of kimchi made with Korean or Japanese baechu cabbage and recipes. J Korean Soc Food Sci Nutr, 42, 520-526

5. Park KY, Rhee SH (2005) Functional foods from fermented vegetable products; kimchi (Korean fermented vegetables) and functionality. In: Asian Functional Foods, 
Shi J, Ho CT, Shahidi F (Editor), Boca Raton, FL, USA, p 341-380

6. Kwon JY, Cheigh HS, Song YO (2004) Weight reduction and lipid lowering effects of kimchi lactic acid powder in rats fed high fat diets. Korean J Food Sci Technol, 36, 1014-1019

7. Cheigh HS, Song YO (2000) Anti-arteriosclerotic and anti-aging functionality of Kimchi. Research Bulletin of Kimchi Science and Technology, 6, 132-140

8. Cho EJ, Choi JS, Kim SH, Park KY, Rhee SH (2004) In vitro Anticancer effect of active compounds from Chinese cabbage kimchi. Journal of Korean Association of Cancer Prevention, 9, 98-103

9. Lee JJ, Lee YM, Kim AR, Chang HC, Lee MY (2008) Effect of Leuconostoc kimchii GJ2 isolated from kimchi (fermented Korean cabbage) on lipid metabolism in high cholesterol-fed rats. Korean J Food Preserv, 15, 760-768

10. Kim M, Lee SJ, Seul KJ, Park YM, Ghim SY (2009) Characterization of antimicrobial substance produced by Lactobacillus paraplantarum KNUC25 isolated from kimchi. Kor J Microbiol Biotechnol, 37, 24-32

11. Han JS, Cho YS, Lee SJ (2003) A comparison on the quality characteristics of Korean and Japanese commercial baechu kimchi. Journal of the Korean Home Economics Association, 41, 85-92

12. Ku KH, Lee KA, Park WS (2006) Quality characteristics of Baechukimchi added ginseng during fermentation periods. J Korean Soc Food Sci Nutr, 35, 1444-1448

13. Shin JH, Kim RJ, Kang MJ, Kim GM, Sung NJ (2012) Quality and fermentation characteristics of garlic-added kimchi. Korean J Food Preserv, 19, 539-546

14. Aguayo E, Escalona VH, Artes F (2008) Effect of hot water treatment and various calcium salts on quality of fresh-cut 'Amarillo' melon. Postharvest Biol Technol, 47, 397-406

15. Klaiber RG, Baur S, Wolf G, Hammes WP, Carle R (2005) Quality of minimally processed carrots as affected by warm water washing and chlorination. Innovative Food Sci Emerging Technol, 6, 351-362
16. Li Y, Brackett RE, Shewfelt RL, Beuchat LR (2001) Changes in appearance and natural microflora on iceberg lettuce treated in warm, chlorinated water and then stored at refrigeration temperature. Food Microbiol, 18, 299-308

17. Kim SS, Ku KH, Jeong MC, Hong JH, Chung SK (2014) Effects of pre-heat treatments on the quality of cut Kimchi cabbages during short-term storage. Korean J Food Preserv, 21, 776-783

18. Park SW (1999) Effects of calcium on cell wall metabolism and ripening of horticultural products. Kor J Hort Sci Technol, 17, 377-380

19. Kim SS, Seong GU, Hwang HY, Jeong MC, Chung SK (2014) The short-term storage characteristics of cut Kimchi cabbages treated with $\mathrm{Ca}^{2+}$. Korean J Food preserv, 21, 157-162

20. Seong GU, Chung HS, Chung SK (2017) Effects of egg shell calcium treatments on the short-term storage of cut Kimchi cabbage, Korean J Food preserv, 24, 1-7

21. Food Code (2015) Ministry of Food and Drug Safety

22. Kim HY (2001) Description analysis of baechu Kimchi. Research Bulletin of Kimchi Science and Technology, 7, 145-154

23. Park WP, Kim CH, Cho SH (2006) Quality characteristics of cherry tomato and unshiu orange packaged with box incorporated with antimicrobial agents. Korean J Food Preserv, 13, 273-278

24. Hong SI, Son SM, Chung MS, Kim DM (2003) Storage quality of minimally processed onions as affected by seal-packaging methods. Korean J Food Sci Technol, 35, 1110-1116

25. Han ES, Seok MS, Park JH (1998) Quality changes of salted Baechu with packaging methods during long term storage. Korean J Food Sci Technol, 30, 1307-1311

26. Kim DM (2014) Quality characteristics of kimchi prepared with various salt type and concentration. MS Thesis, Duksung Woman's University, Korea, p 12

27. Cheigh HS (1995) Critical review on biochemical characteristics of kimchi (Korean fermented vegetable products). J East Asian Soc Dietary Life, 5, 89-101 